\title{
Autophagy-enhancing and neuroprotective effects of Wonji-Gobon mixture (WGM) in a Parkinson's disease mouse model
}

\author{
Jin-Wook Lee ${ }^{1} \cdot$ Jin-Young Kwak ${ }^{2} \cdot$ Young-Mee Koh' ${ }^{2}$ Taek-Won Ahn' \\ Received: 25 April 2018 / Accepted: 17 October 2018 / Published Online: 31 December 2018 \\ (C) The Korean Society for Applied Biological Chemistry 2018
}

\begin{abstract}
The aim of this study was to evaluate autophagyenhancing and neuroprotective effects of Wonji-Gobon mixture (WGM), a traditional Chinese prescription medication, in Parkinson's disease (PD) mouse models. Our investigation found that WGM increased the expression of both Beclin1 and LC3b- $I$ proteins as measured with western blot in the BV2 cell line; both proteins play a role in autophagy. WGM also increased the autophagy expression as measured by fluorescence-activated cell-sorting analysis in the BV2 cell line. In 1-methyl-4-phenyl-1,2,3,6-tetrahydropyridine-induced PD models, WGM significantly increased the amount of dopamine in a striatum-substantia nigra suspension, produced notable results in the forced swim test, and increased serotonin as measured by high-performance liquid chromatography analysis; these results are indicative of neuroprotective effects. In summary, our findings indicate that WGM treatment has neuroprotective effects that are partially mediated by autophagy enhancement.
\end{abstract}

Keywords Autophagy · Dopamine · Neuroprotection · Parkinson's disease $\cdot$ Wonji-Gobon mixture

Taek-Won Ahn $(\triangle)$

E-mail: twahn@dju.kr

${ }^{1}$ Misoro Oriental Clinic, 1590, Bongyeong-ro, Yeongtong-gu, Suwon-si, Gyeonggi-do, Republic of Korea

${ }^{2}$ Department of Sasang Constitutional Medicine, Cheonan Oriental Medicine Hospital of Daejeon University, 4, Notaesan-ro, Seobuk-gu, Cheonan-si, Chungcheongnam-do 331-958, Republic of Korea

This is an Open Access article distributed under the terms of the Creative Commons Attribution Non-Commercial License (http://creativecommons. org/licenses/by-nc/3.0/) which permits unrestricted non-commercial use, distribution, and reproduction in any medium, provided the original work is properly cited.

\section{Introduction}

Parkinson's disease (PD) is a typical degenerative cerebroneural disease that most commonly affects the extrapyramidal system of brain tissue [1]. PD, first reported by James Parkinson in 1817, is related to the extensive degeneration of dopamine within nigrostriatal neurons. Although the disease rate has been lowered through physiological and pathological studies on PD, its cause has not been clearly identified. PD is characterized by motor system dysfunction that may include rigidity, tremors, bradykinesia, hypomimia, dystonia, dysarthria, dyspepsia, micrographia, autonomous dysfunctions, nonmotor dysfunction such as sensory disturbance, and cognitiveneural behavioral dysfunction such as dementia [2]. Depressive symptoms constitute the most common nonmotor symptom of PD and are observed in $35 \%$ of PD patients. The depression rate among PD patients in Korea is reported to be $37.4 \%$ [3]. Depression also has a negative effect on cognitive function, and thus leads to increased frequency of dementia when left untreated [4].

Pathologically, when functional failures occur in mitochondria, the resulting increase in the number of free radicals causes a decline in adenosine triphosphate levels, which in turn generates corpuscula called Lewy bodies [5]. Once the corpuscula are produced, abnormalities occur in protein-decomposing mechanisms such as the ubiquitin-proteasome system and the autophagylysosomal pathway, and may be accompanied by abnormal protein folding; these abnormalities induce decomposition malfunctioning that causes death of dopaminergic neurons [6-8]. Thus, research on decomposing protein aggregates generated by abnormal responses is critical to ultimately curing PD.

Autophagy is a process in which incorrectly produced proteins or matter that has fulfilled its role in a cell is decomposed and eradicated, thereby preventing damaged or disfigured proteins from accumulating within the cell and disturbing its functions [9]. Autophagy is an intracellular dissolution process. When there are insufficient nutrients or a severe external stimulus, cells respond by dissolving old proteins and function as housekeepers. Thus, autophagy is considered an important mechanism that not only 
controls cell death but that is also related to homeostasis and the regulation of cell regeneration [5,10-13]. Abnormal autophagy mechanisms have been found in patients with degenerative brain disease, cancer, or tumors and those who are aging or have various immune diseases [14-17]. The facilitation of autophagy may not only cure degenerative nerve illness by removing abnormal matter but may also work to prevent such diseases-especially in case of nerve degenerative diseases like PD in which abnormal matter builds up within nerve cells and triggers cell toxicity, [10].

Wonji is created by drying the root of the perennial plant Polygala tenuifolia Willd., which is also known as Geranium palustre Polygalaceae. Its taste is bitter and spicy, and its character is mildly warm. It acts to relieve mental stress and promote wisdom, dispel phlegm and promote enlightening, relieve pain, and easily penetrate blockages of the heart and spirit. In addition, Wonji heals abstraction, palpitations, sleep disorders, forgetfulness, and relieves swelling generated by dampness and phlegm-disturbing meridians [18]. Wonji is used clinically to stabilize the nervous system [19].

Gobon is the root of the perennial plant Ligusticum sinense Oliv., which belongs to the Apiaceae family. Gobon relieves pathogenic wind and diffuses cold, dampness, and pain, so is used to treat colds, chills, fevers, headaches without sweat, body and joint pain, and other symptoms related to wind-cold. Recently, Gobon has been used more broadly to cure allergic diseases [20]. Gobon enters the bladder meridian, so it is known to be effective on headaches resulting from externally contracted wind-cold [21]. It enables blood to flow easily and heals headaches that are difficult to recover. Clinicial trials of Shinchultang and Kanghwanseongseuptang, both of which contain Gobon, are underway for use in curing headaches and improving systemic circulation. Gobon has been known as a cure for painful swelling or pain caused by a knotted stomach, as it is known to free blocked parts and to send yang energy to the upper body [22].

There have been numerous studies of Wonji, particularly regarding its neuroprotective, antidementia, and antidepressant effects. Ha conducted research on the prevention of stress-induced behavioral phenotypes using Wonji to treat posttraumatic stress disorder in mice [19], and Koo found Wonji to be effective in controlling the decreasing thickness of the hippocampus and number of neurocytes caused by decreased cerebral blood flow [23]. Park discovered that an ethanol extract of Wonji acts on the glutamate synaptic ionic receptor $\alpha$-amino-3-hydroxy-5-methyl-4-isoxazolepropionic acid to produce an antidepressive effect [24].

More recent studies of Wonji have mainly focused on the treatment of neural degenerative diseases because of its mental stress-relieving and wisdom-promoting effects. In fact, Bae found that Raphani Semen and Wonji are among various herbs in modified Yeoldahanso-tang that induce autophagy [25]. Another important study using Gobon is Choi's (2009) research on the inhibitory effect of Angelicae tenuissimae Radix on mast cell degranulation-mediated allergic reactions [26].
However, there has been insufficient research on the effects and mechanisms related to the mixed extracts of Wonji and Gobon. Previous studies on autophagy related to PD include Bae's research confirming the effects of modified Yeoldahanso-tang on cell proliferation, protection from 1-methyl-4-phenyl-1,2,3,6tetrahydropyridine (MPTP) toxicity, autophagy enhancement, and disintegration of abnormal proteins [25]. Kim et al. also demonstrated the autophagy-inducing properties of Yeoldahanso-tang [27]. Studies on autophagy continue, but studies of drugs other than Yeoldahanso-tang-specifically, studies of Wonji and Gobon extracts-are nonexistent. The rapidly aging population is causing sharp increases in the prevalence of degenerative brain diseases, and interest in PD is growing concomitantly. There is no clear medical treatment for the cognitive disorders and depressive symptoms related to PD, so effective countermeasures are needed. This study aimed to investigate the effects of Wonji-Gobon mixture (WGM) on a BV2 cell line and to confirm its neurocyte protective effects.

\section{Materials and Methods}

\section{Medicinal plants}

The medicinal plants used in this experiment were selected and purchased by Cheonan Oriental Hospital (Daejeon, Korea). All traditional Korean herbs were identified and authenticated by Dr. Taek-Won Ahn of the Botany and Drug Department of Oriental Hospital at Daejeon University, Korea, in accordance with the Korean Herbal Pharmacopoeia (The Korea Food and Drug Administration, 2002). The specimens were deposited in the herbarium of the Natural Products Research Center, Korea Institute of Oriental Medicine, with the following voucher numbers attached: P. tenuifolia Willd., YNJ-0122 and L. sinense Oliv., GOB-0004. The aerial parts of P. tenuifolia Willd. and the root were collected from Sichuan, China. The aerial parts of $L$. sinense Oliv., the root, and the rhizome were collected from Jecheon, Korea. WGM comprises $P$. tenuifolia Willd. and $L$. sinense Oliv.

\section{Preparation of WGM}

Twenty grams (dry weight) of $P$. tenuifolia Willd. and $20 \mathrm{~g}$ of $L$. sinense Oliv. were harvested and air-dried in the shade. The plants were cleaned, cut into small pieces, and then mixed according to the weight ratio. After adding an amount of water equal to four times the weight of the plants, the mixture was boiled in a ceramic pot at $95{ }^{\circ} \mathrm{C}$ for $3 \mathrm{~h}$. The liquid was filtered and enriched by use of a rotary vacuum evaporator. The extract was then fully dried with a freeze dryer and stored in a freezer $\left(-84{ }^{\circ} \mathrm{C}\right)$; it was then diluted into moderate concentrations for use.

\section{Cell culture}

BV2 cells (Korean Cell Line Bank, Seoul Korea) were maintained 
in high-glucose Dulbecco's Modified Eagle Medium (DMEM) (Gibco, Logan, UT, USA) supplemented with $10 \%$ fetal bovine serum (FBS) (Gibco), and antibiotics in a $5 \% \mathrm{CO}_{2}$ incubator at 37 ${ }^{\circ} \mathrm{C}$ and constant humidity.

\section{Animals and treatment}

C57BL/6 mice (male; aged 6 weeks, weight: 20-22 g) were provided with antibiotic-free solid food (Samyang Feed Co., Korea) and water until the day of experiment and were housed under conditions of constant temperature $\left(22 \pm 2{ }^{\circ} \mathrm{C}\right)$, humidity (55 $\pm 15 \%)$ and controlled lighting (12/12 light-dark cycle) for 1 week. The experiment was approved by the Daejeon University animal testing ethics committee for ethical and scientific feasibility in animal testing, and for efficient management (approval number DJUARB2013-042). C57BL/6 mice were injected intraperitoneally with MPTP once per day for $5 \mathrm{~d}$. The mice were isolated for $2 \mathrm{~d}$, and the unabsorbed and discharged results were removed. The mice were then moved to a breeding room where WGM and LDOPA (Madopar; Roche Products Ltd., Welwyn Garden City, UK) were orally administered.

\section{Reagents and equipment}

The following reagents were used in this experiment: 3-(4,5dimethyl-2-thiazolyl)-2,5-diphenyl-2H-tetrazolium bromide (MTT), diethyl pyrocarbonate, chloroform, trichloroacetic acid, isopropanol, Tris- $\mathrm{HCl}, \mathrm{KCl}, \mathrm{MgCl}_{2}$, ammonium-chloride-potassium lysis solution, DMEM, Dulbecco's phosphate-buffered saline, 2-isopropanol, sodium dodecyl sulfate (SDS), streptomycin (Sigma-Aldrich, St. Louis, MO, USA), FBS, Trizol (Ambion, Inc., Austin, TX, USA), deoxynucleoside triphosphate (TaKaRa, Shiga, Japan), Moloney Murine Leukemia Virus Reverse Transcriptase (Promega Corp., Madison, WI, USA), RNase inhibitor (Promega), and an autophagy detection kit (abcam, Cambridge, MA, USA). Rabbit anti-Beclin1, goat anti-LC3b-I, and rabbit anti-LC3b-II (Santa Cruz Biotechnology, Inc., Dallas, TX, USA) were also used. The following equipment was used in this experiment: a hot water extractor (DWT-1800T; Daewoong, Seoul, Korea), rotary vacuum evaporator (BUCHI B-480; BÜCHI Labortechnik AG, Flawil, Switzerland), freeze dryer (EYELA FDU-540; Japan), $\mathrm{CO}_{2}$ culture medium (Forma Scientific Co., Waltham, MA, USA), centrifuge (Hanil Scientific Inc., Gimpo, Korea), plate shaker (Lab-Line, Waltham, MA, USA), spectrophotometer (Shimadzu, Kyoto, Japan), bio-freezer (Sanyo, Moriguchi, Japan), Quantitative Real-Time PCR (Applied Biosystems, Foster City, CA, USA), ELISA leader (Molecular Devices, LLC, San Jose, CA, USA), and high-performance liquid chromatography (Waters Corp., Milford, MA, USA).

Autophagy expression after WGM treatment of BV2 cell line BV2 cells were divided into 24 -well plates with $1 \times 10^{4}$ cells/well, and the samples were pretreated according to concentrations. The cells were incubated for $24 \mathrm{~h}$ in a $5 \% \mathrm{CO}_{2}$ incubator under
DMEM FBS $10 \%$ and constant $37^{\circ} \mathrm{C}$ temperature conditions; 50 $\mu \mathrm{L}$ of the cultured fluid was added to each well of the 96-well plates, and the same volume of the cytotoxity assay kit substrate (Promega) was added. After $30 \mathrm{~min}$, a stop solution was added to end the reaction, and absorbance was measured at $490 \mathrm{~nm}$ wavelength. BV2 cells were divided into 96-well plates with $1 \times 10^{4}$ cells/well and the samples were pretreated according to concentrations. The cells were incubated for $24 \mathrm{~h}$ in a $5 \% \mathrm{CO}_{2}$ incubator under DMEM FBS $10 \%$, and constant $37^{\circ} \mathrm{C}$ temperature conditions; $20 \mu \mathrm{L}$ of 3-(4,5-dimethylthiazol-2-yl)-5-(3-carboxymethoxyphenyl)-2-(4-sulfophenyl)-2H-tetrazolium, inner salt + phenazine methosulfate was then added to each well of the 96well plates, and absorbance was measured at $490 \mathrm{~nm}$ wavelength after $1 \mathrm{~h}$ incubation at $37^{\circ} \mathrm{C}$.

After cleaning the cultivated cell twice with PBS and adding $500 \mu \mathrm{L} / \mathrm{mL}$ lysis buffer $(0.1 \mathrm{M}$ Tris- $\mathrm{HCl}, \mathrm{pH} 7.2,1 \% \mathrm{NP}-40$, $0.01 \%$ SDS, $1 \mathrm{mM}$ phenylmethylsulfonyl fluoride [PMSF], 10 $\mu \mathrm{L} / \mathrm{mL}$ leupetin, $1 \mu \mathrm{L} / \mathrm{mL}$ aprotinin), it was detached and moved to the Eppendorf tube. The transferred cell was vortexed and kept in ice for $15 \mathrm{~min}$ before centrifugation for $15 \mathrm{~min}$ at 13,000 rpm. The supernatant liquid attained from the centrifuge then went through a protein determination process using the Bradford assay procedure (\#500-0002; Bio-Rad Laboratories, Hercules, CA, USA), and an equal amount of protein $20 \mu \mathrm{L} / \mathrm{mL}$ was electrophoresed with $10 \%$ SDS-polyacrylamide gel electrophoresis (PAGE). The electrophoresed protein was moved to a polyvinylidene fluoride (PVDF) membrane (Immobilon-P; Millipore Sigma, Burlington, MA, USA) and blocked at room temperature for $1 \mathrm{~h}$ in the agitator with blocking buffer (5\% skim milk in Tris-buffered saline [TBS]: $2 \mathrm{mM}$ Tris, $50 \mathrm{mM} \mathrm{NaCl}$, pH 7.4)]. The blocked membrane was cleansed three times every 10 min with TBS-T $(0.05 \%$ Tween 20 in TBS); and the primary antibody was diluted in the locking buffer at 1:3,000 and kept in the $4{ }^{\circ} \mathrm{C}$ chamber for overnight reaction. After cleansing the reacted membrane six times with TBS-T, secondary antibody (peroxidase-conjugated anti-mouse or antirabbit) diluted at 1:3,000 was added and kept at room temperature for $1 \mathrm{~h}$ for the reaction. The reacted membrane was once again cleansed six times with TBS-T, and the PVDF membrane was treated with ECL (Amersham plc, Amersham, UK) and observed with LAS-3000. $\beta$-Actin was used as a loading control.

At $24 \mathrm{~h}$ after extracting the $1 \times 10^{6} \mathrm{BV} 2$ cell onto a $100-\mathrm{mm}$ cell culture dish, each dish was treated with $50 \mu \mathrm{g} / \mathrm{mL}$ WGM for 24 h. Rapamycin was processed at $200 \mathrm{nM}$ for $6 \mathrm{~h}$ as a positive control. The BV2 cell was retrieved, and a $5 \times 10^{5}$ cell was inserted in the fluorescence-activated cell-sorting (FACS) tube and washed once with $1 \times$ assay buffer. After sinking the cell by centrifuging at $1000 \mathrm{rpm}$ and suspending in $250 \mu \mathrm{L} 1 \times$ assay buffer, green stain solution from the autophagy detection kit (abcam) was diluted with $250 \mu \mathrm{L} 1 \times$ assay buffer and then inserted into the FACS tube. Light tapping was followed by a 30 -min incubation period in a $37^{\circ} \mathrm{C}$ dark environment and then by washing three times with $1 \times$ assay buffer. The wavelength (FL1) from each 
sample was graphed by histogram using FACSCalibur (BD Bioscience, San Jose, CA, USA).

\section{High-performance liquid chromatography analysis of WGM} active components

High-performance liquid chromatography (HPLC) was performed at $40{ }^{\circ} \mathrm{C}$ oven temperature, $325 \mathrm{~nm}$ analytic wavelength, and 1.0 $\mathrm{mL} / \mathrm{min}$ flow rate using a and Luna C18 column $(250 \mathrm{~mm} \times 4.6$ $\mathrm{mm}$; particle size: $5 \mu \mathrm{m}$; Phenomenex, Torrance, CA, USA). For the mobile phase, $100 \%$ third distilled water (containing $0.1 \%$ trifluoroacetic acid) was used for solvent $\mathrm{A}$, and $100 \%$ acetonitrile with $0.1 \%$ formic acid added was used for solvent $\mathrm{B}$. The reference sample and the WGM component of chlorogenic acid were analyzed.

\section{Measurement of dopamine in a striatum-substantia nigra suspension}

The brains of two mice per group were removed and frozen at $-20{ }^{\circ} \mathrm{C}$. The brain specimens (striatum-substantia nigra portion) were separated, and 200-500 $\mu \mathrm{L}$ extraction buffer ( $0.3 \mathrm{M}$ sucrose, $0.15 \mathrm{mM}$ spermine, $0.5 \mathrm{mM}$ spermidine, $10 \mathrm{mM}$ HEPES [pH 7.9], $1.5 \mathrm{mM} \mathrm{MgCl}_{2}, 10 \mathrm{mM} \mathrm{KCl}, 0.5 \mathrm{mM}$ DTT, $0.2 \mathrm{mM}$ PMSF, $0.1 \%$ protease inhibitor, $0.1 \%$ phosphatase inhibitor, and $0.5 \% \mathrm{NP}$ 40) was added to the brain specimens. After homogenization, extraction buffer was added and well mixed until the final volume reached $0.2 \mathrm{~mL}$; the specimen then underwent dissolution for $2 \mathrm{~h}$ at $4{ }^{\circ} \mathrm{C}$. When the reaction ended, the specimen was placed in a $1.5-\mathrm{mL}$ tube and vortexed five times for $3 \mathrm{~min}$ each. After $15 \mathrm{~min}$ of centrifugation, the supernatant $(100 \mu \mathrm{L})$ was collected. The protein volume was measured by Bradford method using the BioRad protein analyzing kit. Using a Mouse/Rat Dopamine ELISA Assay Kit (DOU39-K01; Eagle Biosciences, Inc., Nashua, NH), each well was washed with wash buffer following the manufacturer's instructions, and $100 \mu \mathrm{L}$ assay diluent was placed in each well. Samples were cultivated for $1 \mathrm{~h}$ in a blocked well at room temperature. After the standard solution was diluted and the supernatant was diluted 20 times, the origin, the standard solution, and the supernatant were placed in $100-\mu \mathrm{L}$ washed microplates. The wells were then blocked and cultivated at room temperature. Microplates were washed, and warking detector were placed in $100-\mu \mathrm{L}$ wells; the specimens were cultivated for $1 \mathrm{~h}$ in their blocked wells at room temperature. Microplates were washed, and substrate solutions were placed in $200-\mu \mathrm{L}$ wells and cultivated for $30 \mathrm{~min}$ in a dark place at room temperature. We then added $50 \mu \mathrm{L}$ stop solution to each well and analyzed samples with a microplate spectrophotometer at $450 \mathrm{~nm}$ absorbance.

\section{Effects of WGM on depression symptoms}

Forced swim tests were conducted for $2 \mathrm{~d}$; results were measured on the second day. On the first day, a round acrylic cylinder with its upper side open ( $20 \mathrm{~cm}$ diameter, $40 \mathrm{~cm}$ height) was filled with clean water $\left(25 \pm 2{ }^{\circ} \mathrm{C}\right.$ water temperature $)$ to a height of $15 \mathrm{~cm}$, and depressive mouse models were forced to swim for $15 \mathrm{~min}$. After $15 \mathrm{~min}$, they were raised out of the water, wiped with dry cloths, and placed back into the breeding cage (pretest session). After 24 $\mathrm{h}$, the animals were placed in the same equipment for $5 \mathrm{~min}$ and forced to swim. Their swimming, immovable behaviors, and climbing behaviors were observed (test session). The forced swimming test behavior was videotaped for later analysis and the periods of immobility were scored using the tapes.

The brains of two mice per group were separated and homogenized; $5 \mathrm{~mL}$ ethanol was added to the brains, and each was cultured in a shaking water bath for more than $6 \mathrm{~h}$. The samples were then concentrated with pressure to reach $0.2 \mathrm{~mL}$. The concentrated extraction was analyzed by HPLC to assess dopamine, serotonin, melatonin, epinephrine, and norepinephrine levels. The Agilent 1200 series HPLC (Waters Co.) includes an autosampler, column oven, and binary pump, and is intended for analysis of brain extracts. The system was used together with a diode array detector (Agilent Technologies, Waldbronn, Germany) and degasser (Agilent Technologies, Tokyo, Japan). Chemstation software (Agilent Technologies, Avondale, CA, USA) was used for analysis.

\section{Statistical analysis}

All results are presented as means \pm standard errors. All statistical analyses were performed with SPSS 10.0 (Evanston, IL, USA) software. Tests of significance were conducted using Tukey's HSD test after analysis of variance ( $t$-test). Significance was set at $\alpha=0.05(* p<0.05, * * p<0.01, * * * p<0.001)$.

\section{Results}

\section{Autophagy}

Autophagy expression after WGM treatment was evaluated by using a BV2 cell line treated with WGM. At $24 \mathrm{~h}$ after treatment of the BV2 cell line with varying doses of WGM, culture fluid was collected, and lactate dehydrogenase (LDH)-release and MTT assays were performed. No cytotoxicity was observed at concentrations of $5-50 \mu \mathrm{g} / \mathrm{mL}$, based on LDH release (Fig. 1A), or at 5-100 $\mu \mathrm{g}$ / $\mathrm{mL}$, based on cell viability (Fig. 1B). Based on results of the LDH-release and MTT assays, the appropriate concentrations of WGM for the following experiments were set at 25 and $50 \mu \mathrm{g} /$ $\mathrm{mL}$.

At $24 \mathrm{~h}$ after the $50 \mu \mathrm{g} / \mathrm{mL}$ and $25 \mu \mathrm{g} / \mathrm{mL}$ WGM treatment of BV2 cell lines, the cells were collected and protein levels were examined using western blotting. Levels of Beclin1 and LC3bincreased, indicating autophagy (Fig. 2).

BV2 cell lines were treated with $50 \mu \mathrm{g} / \mathrm{mL}$ WGM and $200 \mathrm{nM}$ rapamycin for $6 \mathrm{~h}$. FACS analysis revealed $75.35 \%$ increase in autophagy activity (Fig. 3). 

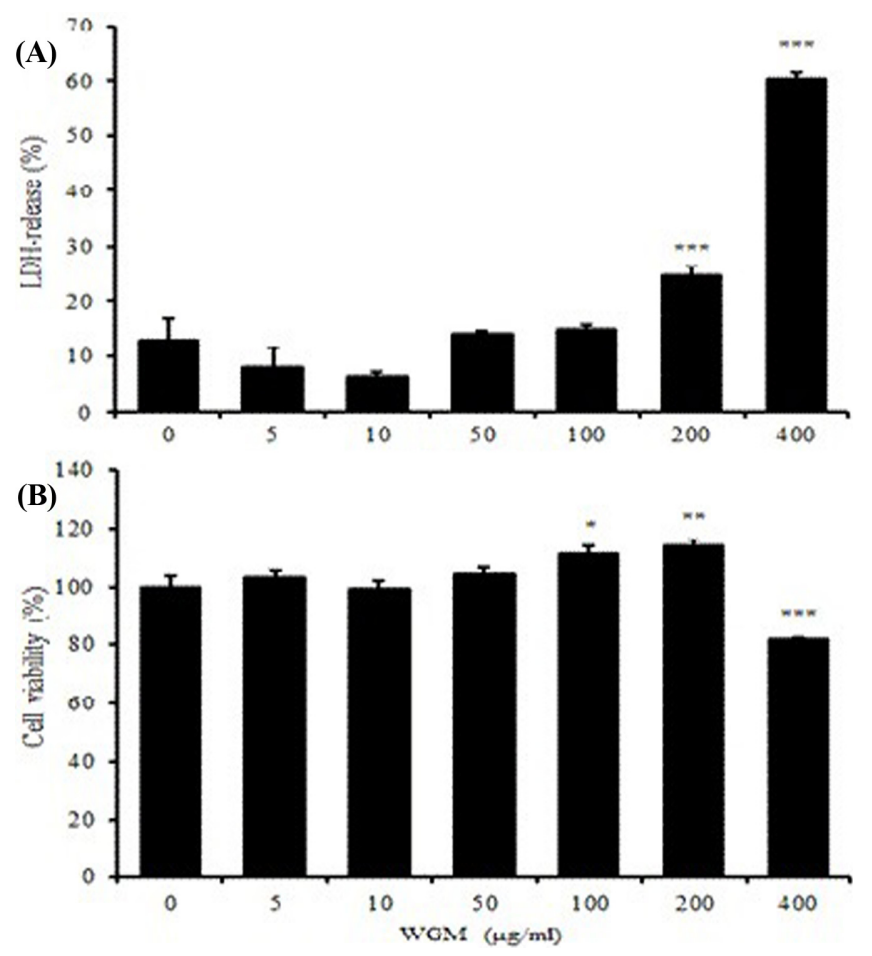

Fig. 1 The effect of Wonji-Gobon mixture (WGM) on lactate dehydrogenase (LDH) release in BV2 microglia cells. BV2 microglia cells $\left(2 \times 10^{5}\right.$ cells/well in 24-well plates) were pretreated with WGM for $24 \mathrm{~h}$. BV2 microglia cells were pretreated with various concentrations of WGM extract $(5,10,50,100,200,400 \mu \mathrm{g} / \mathrm{mL})$ for $48 \mathrm{hr}$. The culture supernatant was collected $24 \mathrm{~h}$ later, and (A) LDH release and (B) 3-(4,5dimethyl-2-thiazolyl)-2,5-diphenyl-2H-tetrazolium bromide (MTT) in the supernatant were assayed. Results are presented as means \pm standard errors of three experiments. $(* * p<0.01, * * * p<0.001)$

\section{HPLC analysis of WGM active components}

To identify standard substances contained in the WGM component, correspondence of retention times between WGM and standard chlorogenic acid was evaluated with HPLC-diode-array detection (DAD). The content of chlorogenic acid in WGM was determined to be $2.52 \mathrm{mg} / \mathrm{g}$ (Fig. 4).

\section{Dopamine protective effects}

The amount of dopamine was directly measured using a striatumsubstantia nigra suspension. The dopamine level of the control group (MPTP-MD group) was more than four times higher than that of the MPTP group, and the dopamine level of MPTP-WGM group was more than three times than that of the MPTP group. These results indicate that WGM substantially increases the amount of dopamine in dopamine-induced mice (Fig. 5) $(* * p<0.01, * * * p<0.001)$.

\section{Effects of WGM on depression symptoms}

To observe changes in depression caused by PD and following bradykinesia, forced swim tests were conducted. The immobility times observed for the MPTP, MPTP-MD, and MPTP-WGM groups were $212,125.7$, and $138 \mathrm{~s}$, respectively. The immobility time for WGM-treated mice was $74 \mathrm{~s}$ shorter than that for mice treated only with MPTP (Fig. 6) $\left(* p<0.05,{ }^{*} p<0.01\right)$.

\section{Serotonin levels}

Prototype assays using HPLC and neurotransmitter analysis demonstrated that among dopamine, serotonin, melatonin, epinephrine, and norepinephrine, only serotonin can be examined with HPLC analysis. Serotonin is involved in the development of depressive symptoms, and serotonin-operative neurological disorders and regression are known to be related to depression in PD patients. To observe the changes serotonin levels, a standard form of serotonin was first examined with HPLC analysis. Serotonin patterns in depressive mice brains were then examined, and standard materials were identified. The volume of serotonin detected was reported in ng/g by measuring the area per weight of brain tissue after the peak area of the graph was calculated. The results indicate that the amount of serotonin generation varied slightly among groups. When the serotonin content of the normal group, MPTP group, MPTP-MD group, and MPTP-WGM group were compared from this reference, the serotonin generation rate of MPTP group had decreased from that of the normal group. The MPTP-MD $(p<0.001)$ and MPTP-WGM groups $(p<0.001)$ also demonstrated statistically significant increases in serotonin generation compared with the MPTP group (Fig. 7).

\section{Discussion}

Previous studies of Wonji and Gobon include research conducted by Yang and others [28]. The main herbal component of their patented product is Lonnag Arillus. The drug was commercialized because of the neurocyte protective and autophagy-inducing effects of Lonnag Arillus and WGM. This mixture promotes dopamine cell protection and improvement of behavioral disorders. In addition, the mixture has a much better LC3- protein expressioninducing effect than does Lonnag Arillus alone. Although this drug contains Lonnag Arillus as its primary herbal component, combining Wonji and Gobon with Lonnag Arillus generates greater neurocyte protection and autophagy-inducing effects than are observed with Lonnag Arillus alone.

Accordingly, this research referred to previous studies that assessed Wonji's brain cell-related effects and Gobon's effects on body circulation and its characteristic of flowing into the top of the head to treat headaches. This study demonstrated the autophagy-inducing effects of WGM and evaluated its effects on behavior and brain neuron cell changes.

Our results indicated that levels of autophagy-related essential proteins Beclin1 and LC3b- increased. At a WGM concentration was of at $25 \mu \mathrm{g} / \mathrm{mL}$, there was no difference in the $\beta$-actin level (a loading control), but when the concentration was increased to $50 \mu \mathrm{g} / \mathrm{mL}$, the $\beta$-actin level doubled. This means that WGM has 

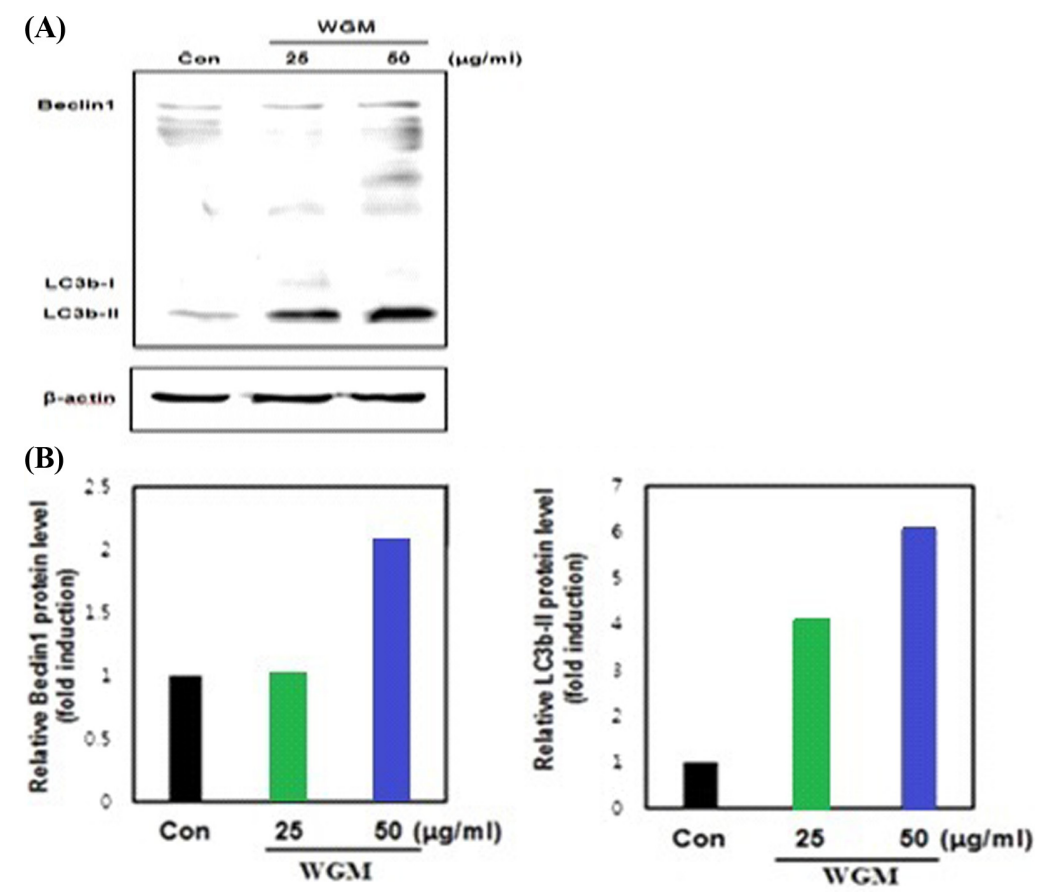

Fig. 2 Effects of Wonji-Gobon mixture (WGM) extract on autophagy-relative protein expression of signal events in BV2 microglia cell lines. BV2 microglia cells were pretreated with $25-\mu \mathrm{g} / \mathrm{mL}$ and $50-\mu \mathrm{g} / \mathrm{mL}$ of WGM extract for $24 \mathrm{~h}$. After adding lysis buffer, samples of the lysates were subjected to western blot with signal protein expression. Other samples of the lysates were directly subjected to sodium dodecyl sulfate-polyacrylamide gel electrophoresis (SDS-PAGE) and immunoblotting. (A) The levels of signal protein expression (LC3b-1, LC3b-II, Beclin1) were selected as positive controls, and internal controls were compared with $\beta$-actin. (B) Beclin1 and LC3b-II protein band densities were compared with $\beta$-actin

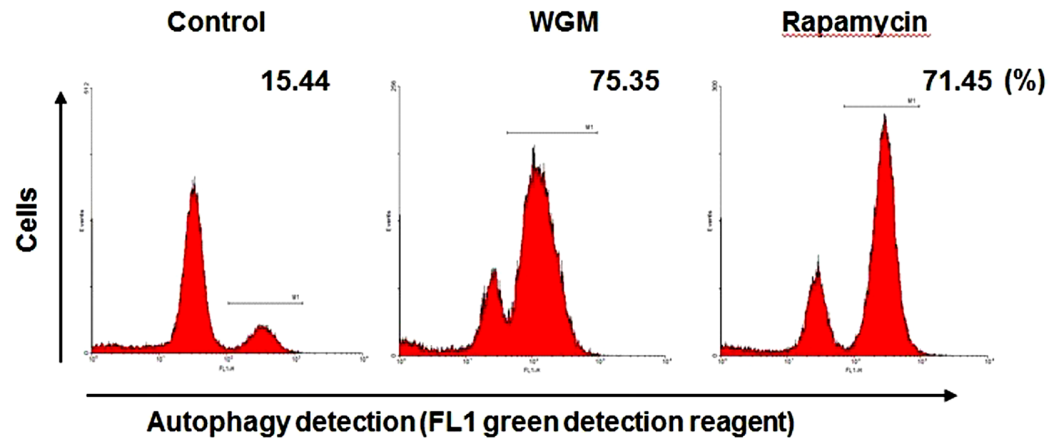

Fig. 3 Effects of Wonji-Gobon mixture (WGM) extract on autophagy detection in a BV2 microglia cell line. BV2 microglia cells were pretreated with $50 \mu \mathrm{g} / \mathrm{mL}$ WGM extract and $200 \mathrm{nM}$ rapamycin for $6 \mathrm{~h}$. Fluorescence-activated cell sorting was used to assess autophagy

a meaningful effect on the expression of Beclin1, an essential protein in the induction of autophagy. LC3b- is an autophagy corpusculum membrane protein, and its increase means autophagy has occurred. This research examined changes in the membrane protein LC3b- that occurred when WGM was administered at 25 $\mu \mathrm{g} / \mathrm{mL}$ and at $50 \mu \mathrm{g} / \mathrm{mL}$. We found that the amount of LC3bmembrane protein increased as the concentration of WGM increased. At $25 \mu \mathrm{g} / \mathrm{mL}$ WGM, more than four times the amount of â-actin (the loading control) was expressed, and more than six times the amount of $\beta$-actin was expressed at $50 \mu \mathrm{g} / \mathrm{mL}$. These results indicate that WGM can induce autophagy.

FACS analysis was performed to determine the total number of autophagy-expressing cells, as determined by microglia that are viable after autophagy expression. Our research showed that more autophagy-related cells were detected in the WGM group than in the rapamycin group. To observe the effects of autophagy expression in real behavioral experiments or the influences it has on dopamine and neural tissues, the standard compounds of WGM were removed, and additional experiments were performed using MPTP-injected PD mouse models.

HPLC analysis was performed on WGM and the standard compound chlorogenic acid, with results reported in terms of retention time as determined by HPLC-DAD. The chlorogenic acid content of WGM was determined to be $2.52 \mathrm{mg} / \mathrm{g}$. Chlorogenic 
(A)

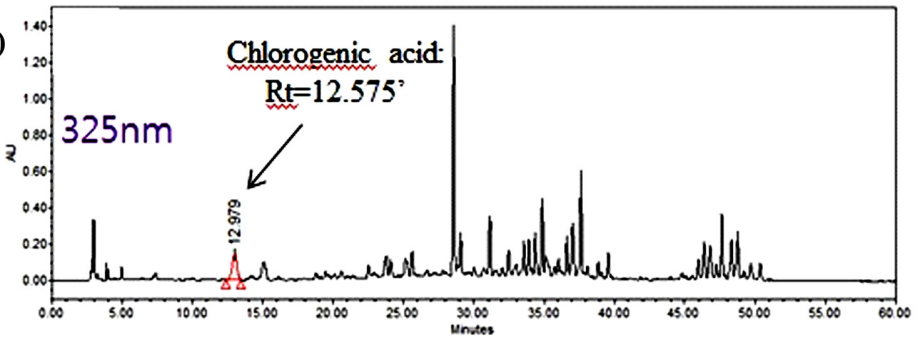

(B)
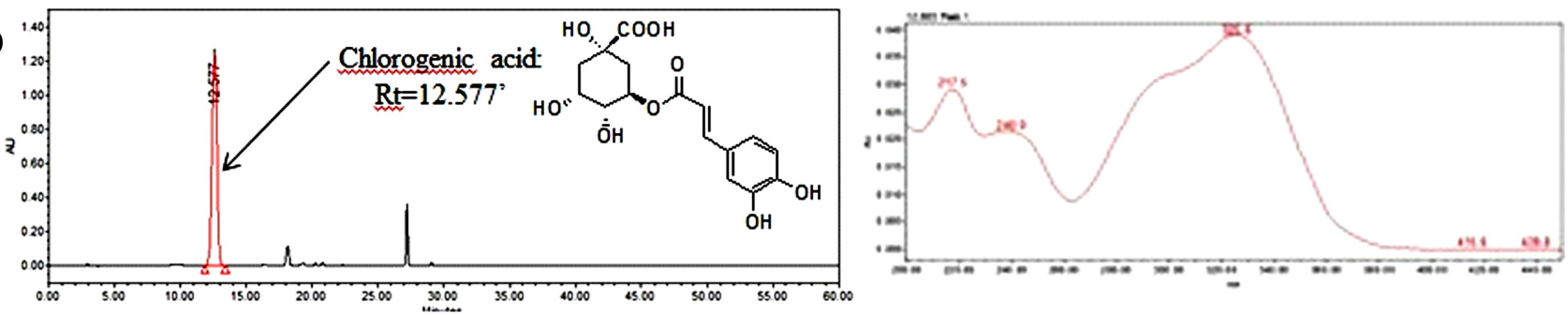

Fig. 4 High-performance liquid chromatography (HPLC) chromatograms of standard Wonji-Gobon mixture (WGM) and chlorogenic acid. Chromatograms of standard (A) WGM and (B) chlorogenic acid were recorded at $325 \mathrm{~nm}$. The peaks for chlorogenic acid are shown

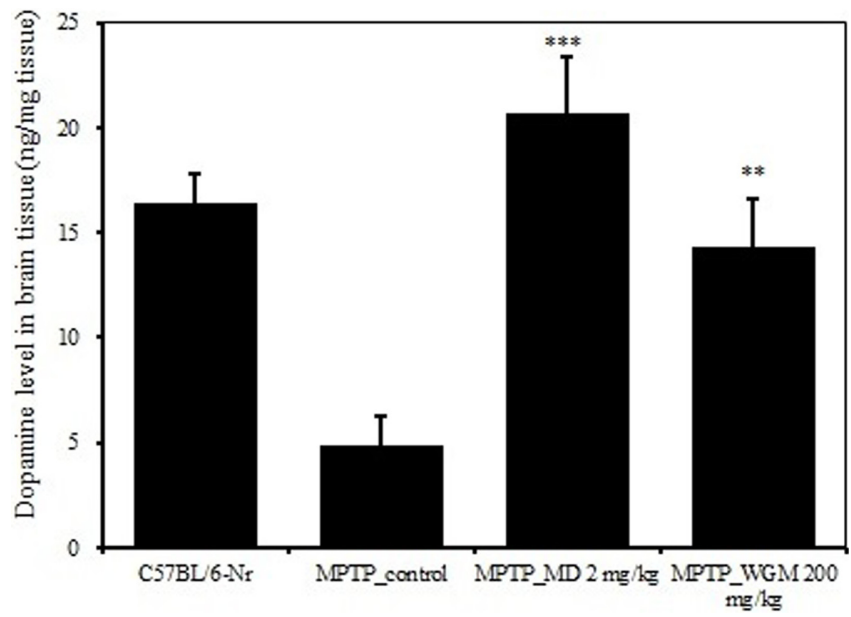

Fig. 5 Effects of Wonji-Gobon mixture (WGM) on dopamine levels in brain tissue of 1-methyl-4-phenyl-1,2,3,6-tetrahydropyridine (MPTP)induced Parkinson's disease (PD) mouse models. C57BL/6 mice were orally administered WGM or L-DOPA (MD). Data are presented as means \pm standard errors $(n=8)$. Statistical significance was determined by comparison with MPTP-induced PD mice (control) data using the $t$-test $\left({ }^{* *} p<0.01,{ }^{* * *} p<0.001\right)$

acid is known for its antioxidant and anti-inflammatory properties, as well as for its antidiabetic effects [29,30]. Min's study indicates that the antioxidant and matrix metalloproteinase (MMP-2, MMP9) control effects protect brain damage from ischemia and enhance motor skills, while also having repressive effects on blood-brain barrier damage and following cerebral edema caused by ischemia [31]. Therefore, the neuroprotective properties of WGM were identified by finding chlorogenic acid in WGM using HPLC active component analysis.

A dopamine neurocyte protective effect was observed after WGM administration. An experiment was conducted to discover

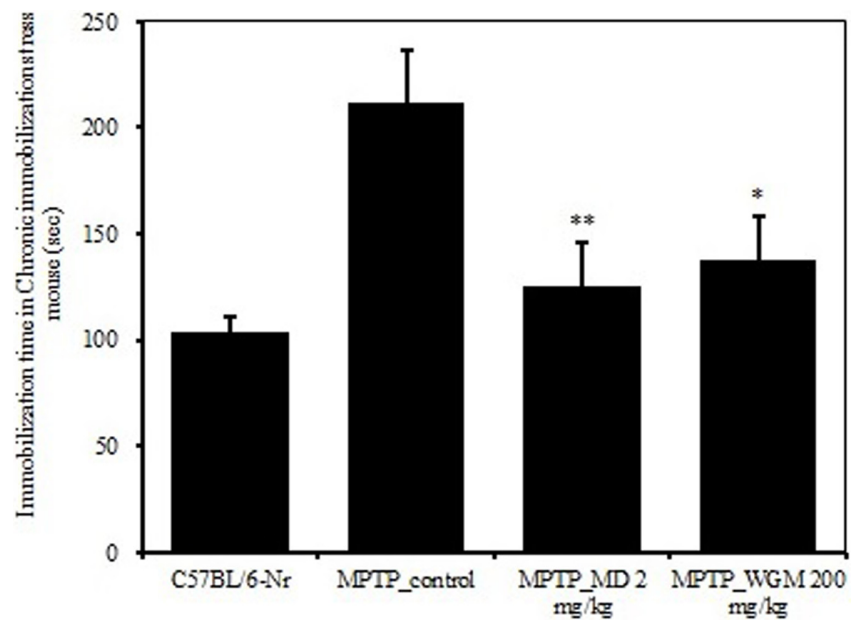

Fig. 6 Effects of Wonji-Gobon mixture (WGM) on immobility time during forced swimming tests in 1-methyl-4-phenyl-1,2,3,6-tetrahydropyridine (MPTP)-induced Parkinson's disease (PD) mouse models. C57BL/6 mice were orally administered with WGM or L-DOPA (MD). Data are presented as means \pm standard errors $(n=8)$. Statistical significance was determined by comparison with MPTP-induced PD mice (control) data using the $t$-test $\left({ }^{*} p<0.05,{ }^{* *} p<0.01\right)$

the amount of dopamine in a striatum-substantia nigra suspension obtained from mice. We found that the dopamine level was approximately three times higher in the MPTP-WGM group than in the MPTP group. This indicates that WGM provides an effective dopaminergic neuroprotective effect to PD patients.

A forced swim text was used to evaluate behavioral effects. Among the symptoms of PD, immobile behaviors include slowed stream of thought, performance dysfunction, and depression that affects $30-60 \%$ of patients [32]. Depression leads to loss of will for action and immobile symptoms. Therefore, the time during which mice had only their heads out of water with no other 


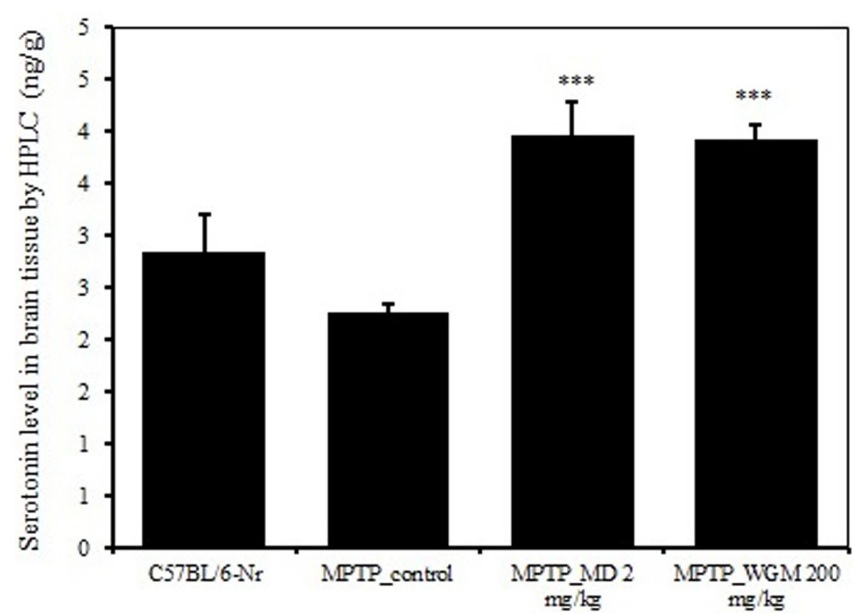

Fig. 7 Effects of Wonji-Gobon mixture (WGM) on serotonin levels in the brain tissue of the 1-methyl-4-phenyl-1,2,3,6-tetrahydropyridine (MPTP)induced Parkinson's disease (PD) mouse models as determined by highperformance liquid chromatography (HPLC). C57BL/6 mice were orally administered WGM or L-DOPA (MD). Data are presented as means \pm standard errors $(n=8)$. Statistical significance was determined by comparison with MPTP-induced PD mice (control) data using the $t$-test $(* * * p<0.001)$

movement was measured in the forced swim test. The immobility time for the MPTP-WGM group was statistically shorter that that for the MPTP-treated group.

HPLC was used to investigate changes in death of dopaminergic neurons caused by PD. Serotonin levels were analyzed using a standard identification method. Serotonin is involved in multiple system atrophy and cognitive disorders, depression, and the worsening of emotional symptoms in PD patients. Thus far, studies on serotonin have primarily examined depression and sleep disorders, with few studies finding a relationship between PD and serotonin. The difference between PD and multiple system atrophy is known to be related to serotonin decrease, but the mechanism remains unclear. In this study, serotonin was detected using HPLC analysis, and serotonin levels for the MPTPWGM group were significantly higher than were those of the MPTP group. When analyzed in conjunction with previous observations that the depression-derived immobile state of the MPTP-WGM group decreased, it would appear that increased levels of serotonin after WGM uptake may play a role in decreasing immobility time.

This study was limited by the number of animal models used, and additional clinical testing in patients with depression resulting from PD is warranted. Moreover, since WGM's protective effects, as determined by serotonin decreases in a PD model were significant, continuous and varying studies in the field are expected.

Our research suggests that an autophagy effect is observed when BV2 cell lines are treated with WGM. The neuroprotective effect of WGM in MPTP-injected PD mouse models was identified by HPLC. Changes in dopamine levels in the striatum- substantia nigra indicated that dopaminergic neurocytes were protected. Decreases in depressive symptoms were observed using forced swim tests and serotonin analysis. In summary, our findings indicate that WGM treatment has neuroprotective effects that are partially mediated by autophagy enhancement.

Acknowledgments This research was supported by the Ministry of Science and ICT 'A clinical study of medications and devices for the treatment of metabolic diseases according to constitutional characteristics.' (Grant No.: 2015M3A59B6028311). This research was also supported by the Daejeon University fund (2016).

\section{References}

1. Lee DH (2005) What is Parkinsonism? 4th ed. Pommunsa, Seoul

2. Jankovic J (2008) Parkinson's disease: clinical features and diagnosis. J Neurol Neurosurg Psychiatry 79: 368-376

3. Lim J, Dinges DF (2010) A meta-analysis of the impact of short-term sleep deprivation on cognitive variables. Psychol Bull 136: 375-389

4. Son JA (2013) Factors influencing depression among older adults in rural areas. Dissertation, Kyungpook University

5. Yoon HJ (2009) The study about the ER stress and autophagy-associated pathogenetic mechanisms in systemic lupus erythematosus. Dissertation, Chonbuk National University

6. Dauer W, Przedborski S (2003) Parkinson's disease: mechanisms and models. Neuron 39: 889-909

7. Eisenberg-Lerner A, Bialik S, Simon H-U, Kimchi A (2009) Life and death partners: apoptosis, autophagy and the cross-talk between them. Cell Death Differ 16: 966-975

8. Mauthe M, Jacob A, Freiberger S, Hentschel K, Stierhof Y-D, Codogno P, Proikas-Cezanne T (2011) Resveratrol-mediated autophagy requires WIPI-1-regulated LC3 lipidation in the absence of induced phagophore formation. Autophagy 7: 1448-1461

9. Kroemer G, Jäättelä M (2005) Lysosomes and autophagy in cell death control. Nat Rev Cancer 5: 886-897

10. Porsolt RD, Bertin A, Blavet N, Deniel M, Jalfre M (1979) Immobility induced by forced swimming in rats: effects of agents which modify central catecholamine and serotonin activity. Eur J Pharmacol 57: 201210

11. Lee J-A (2012) Neuronal autophagy: a housekeeper or a fighter in neuronal cell survival? Exp Neurobiol 21: 1-8

12. Hara T, Nakamura K, Matsui M, Yamamoto A, Nakahara Y, SuzukiMigishima R, Yokoyama M, Mishima K, Saito I, Okano H, Mizushima N (2006) Suppression of basal autophagy in neural cells causes neurodegenerative disease in mice. Nature 441: 885-889

13. Pan T, Rawal P, Wu Y, Xie W, Jankovic J, Le W (2009) Rapamycin protects against rotenone-induced apoptosis through autophagy induction. Neuroscience 164: 541-551

14. Huang J, Klionsky DJ (2007) Autophagy and human disease. Cell Cycle 6: $1837-1849$

15. Massey AC, Zhang C, Cuervo AM (2006) Chaperone-mediated autophagy in aging and disease. Curr Top Dev Biol 73: 205-235

16. Cuervo AM, Dice JF (2000) Age-related decline in chaperone-mediated autophagy. J Biol Chem 275: 31505-31513

17. Cuervo AM, Bergamini E, Brunk UT, Dröge W, Ffrench M, Terman A (2005) Autophagy and aging: the importance of maintaining "clean" cells. Autophagy 1: 131-140

18. Kang BS, Kim YP (1996) Clinical combination herbology for systemic construction of herbal formulas. 2nd edition. Seoul: YoungLim Corporation, pp 309-311

19. Ha SK (2014) Prevention of stress induced behavioral phenotypes by Radix Polygalae in post-traumatic stress disorder mice. Dissertation, 
Kyunghee University

20. Lee SY (1981) Herbology. Suseowon, Seoul

21. Text Book Publication Committee of Oriental Medical Schools in Korea (2005) Herbology. YoungLim, Seoul

22. Ha HY (2013) Shinnongboncho life-nurturing method (Yangsaeng). Gyeonggi-do, Korea: Korean Studies Information, Paju

23. Koo YM (2014) Effects of Polygalae radix on learning and memory impairment in vascular dementia model of rats. Dissertation, Kyunghee University

24. Park SH (2014) Modulation of glutamatergic synaptic function is related to the antidepressant like effect of Polygala tenuifolia Wild extract. Dissertation, Kyunghee University

25. Bae NY (2010) Neuroprotective effect of modified Yeoldahanso-tang via autophagy enhancement on Parkinsonian model. Dissertation, Daejeon University

26. Choi YG (2009) The effect of Angelicae tenuissimae Radix on mast cellmediated allergic inflammatory disease. Dissertation, Wonkwang University
27. Kim H-J, Bae N-Y, Jang M-H, Yang H-O, Ahn T-W (2013) Autophagy inducing effect of modified yeoldahanso-tang and its related proteins in SH-SY5Y cells. J Sasang Constitut med 25: 208-217

28. Yang H-O, Bae N-Y, Kwon H-C, Chung S-K, Oh M-S (2012) Composition comprising longan arillus extract or mixed extracts comprising the same for neurodegenerative diseases. Korea patent 1011891910000 http://engpat.kipris.or.kr/engpat/biblioa.do?method=biblioFrame

29. Oh EJ (1997) Studies on the antioxidative and anti-inflammatory effects of hydroxycinnamic acid derivatives. Dissertation, Dongduc Women's University

30. Yang JS (2009) Hypoglycemic effect of yacon tuber extract and its constituent, chlorogenic acid, in streptozotocin-induced diabetic rats. Dissertation, Chungbuk University

31. Min KY (2012) Neuroprotective effects of chlorogenic acid on transient cerebral ischemia rat model. Dissertation, Kyunghee University

32. Kim HT, Choi JS, Park EH, Lee KH, Kim EJ, Lee YK (2006) Animal behavior test studying brain illness for neurologist. Siguma Puresu, Seoul 